\title{
ANALISIS KLASIFIKASI PERSEDIAAN SUKU CADANG MENGGUNAKAN MUSIC-3D VIEW OF SPARES (Studi Kasus Perusahaan Farmasi di PT. XYZ)
}

\author{
Yuli Dwi Astanti \\ Program Studi Teknik Industri, Fakultas Teknologi Industri \\ Universitas Pembangunan Nasional "Veteran" Yogyakarta \\ Jalan Babarsari No 2 Tambakbayan Yogyakarta \\ email: yulidwi.astanti@upnyk.ac.id
}

\begin{abstract}
PT. $X Y Z$ is a pharmaceutical company that manufactures both pharmaceuticals and herbal medicinal chemistry. The drug is a vital necessity to society, therefore, the drug production process must be maintained so that its performance can be met drug availability. One way to maintain smooth production process is to maintain engine performance. An engine production facility that is vital and requires periodic maintenance or at any time in case of damage. Each performed maintenance or repairs due to damage, an engine needs replacement parts for the machine to run as before. To support the maintenance activities, $P T$. $X Y Z$ has a warehouse used to store spare parts. During this time, parts storage system in PT. XYZ is not based on consideration of the appropriate classification of its characteristics, but each part has different characteristics, both in terms of price, suppliers, materials, usage, and so on. Due to the large number of stocks and the importance of spare parts, the supply system must be considered in order not to cause any harm to the company. The present study will attempt to analyze the system parts inventory in the warehouse by using MUSIC-3D View of Spares. MUSIC-3D View of spares in the analysis using a 3-dimensional approach that values consumption, availability and critically. The third dimension is represented by the three approaches, namely System ABC, VED, and SDE. Based on the results of the analysis of MUSIC-3D Views of Spares in mind that parts each having a different classification, so it requires a different treatment according to their classification.
\end{abstract}

\section{Keywords : spare parts, supplies, MUSIC-3D View of Spares}

PT. XYZ merupakan perusahaan farmasi yang memproduksi obat-obatan baik obat kimia maupun herbal. Obat merupakan kebutuhan vital bagi masyarakat, oleh karena itu, proses produksi obat harus selalu dijaga performansinya agar ketersediaan obat dapat terpenuhi. Salah satu cara menjaga kelancaran proses produksi adalah dengan menjaga performansi mesin. Mesin merupakan fasilitas produksi yang vital dan memerlukan perawatan berkala atau sewaktu-waktu jika terjadi kerusakan. Setiap dilakukan perawatan atau perbaikan karena kerusakan, sebuah mesin memerlukan suku cadang pengganti agar mesin dapat berjalan seperti semula. Untuk mendukung kelancaran aktifitas perawatan tersebut, PT. XYZ mempunyai sebuah gudang yang digunakan untuk menyimpan suku cadang. Selama ini, sistem penyimpanan suku cadang di gudang PT. XYZ tidak berdasarkan pertimbangan pengklasifikasian sesuai karakteristiknya, padahal setiap suku cadang mempunyai karakteristik yang berbeda, baik dari sisi harga, pemasok, bahan, penggunaan, dan sebagainya. Dikarenakan banyaknya jumlah stock dan pentingnya suku cadang, maka sistem persediaannya harus diperhatikan agar tidak menimbulkan kerugian bagi perusahaan. Penelitian kali ini akan berusaha menganalisis sistem persediaan suku cadang di gudang dengan menggunakan MUSIC-3D View of Spares. MUSIC-3D View of Spares dalam analisisnya menggunakan 3 dimensi pendekatan yaitu consumption value, availability dan critically. Ketiga dimensi tersebut diwakili oleh tiga pendekatan yaitu Sistem ABC, VED, dan SDE. Berdasarkan hasil analisis MUSIC-3D Views of Spares diketahui bahwa masing-masing suku cadang mempunyai klasifikasi yang berbeda, sehingga memerlukan penanganan yang berbeda pula sesuai dengan klasifikasinya.

Kata kunci : suku cadang, persediaan, MUSIC-3D View of Spares 


\section{LATAR BELAKANG}

PT. XYZ adalah sebuah perusahaan farmasi yang memproduksi berbagai macam produk obat-obatan. Produk obat adalah produk vital dan sangat dibutuhkan masyarakat. Oleh karena itu, agar dapat terus memenuhi kebutuhan masyarakat, keberlangsungan proses produksi harus tetap stabil dan tidak mengalami penurunan. Terhentinya proses produksi di lantai produksi sering terjadi disebabkan adanya masalah dalam fasilitas produksi. Fasilitas dalam sebuah produksi ada berbagai macam, salah satunya adalah mesin. Sebuah mesin yang berhenti bekerja karena kerusakan berakibat pada berhentinya proses produksi. Terhentinya proses produksi akan membawa kerugian bagi perusahaan karena target produksi yang tidak tercapai. Pada dasarnya, kerusakan mesin bisa terjadi kapan saja. Ada kerusakan yang bisa diprediksi dan ada yang tidak bisa diprediksi. Kerusakan yang bisa diprediksi diantisipasi PT. $\mathrm{XYZ}$ dengan melakukan preventive maintenance atau perawatan untuk mencegah kerusakan. Kerusakan yang tidak dapat diprediksi diantisipasi oleh perusahaan dengan menyiapkan persediaan suku cadang pengganti jika sewaktu-waktu terjadi kerusakan.

PT.X mempunyai dua jenis mesin yaitu mesin produksi dan mesin utitlitas (mesin pendukung proses produksi). Kedua jenis mesin tersebut mempunyai kemungkinan kerusakan pada waktu-waktu yang tidak bisa diprediksi dan sama-sama mempunyai jadwal perawatan berkala. Untuk mendukung kelancaran proses perawatan dan menghindari berhentinya proses produksi karena kerusakan yang terjadi sewaktu-waktu, PT. XYZ mempunyai sebuah gudang khusus untuk penyimpanan suku cadang. Gudang suku cadang di PT. XYZ digunakan untuk menyimpan segala jenis suku cadang yang akan digunakan baik untuk mesin produksi maupun mesin utilitas. Dalam pengelolaannya, sebuah persediaan harus mempertimbangkan klasifikasi barang yang disimpan agar tidak terjadi kekeliruan, keusangan ataupun kerugian bagi perusahaan. Suku cadang merupakan jenis persediaan yang mempunyai karakteristik yang berbeda dengan barang persediaan lain. Pujawan (2010) dalam Apriandana dan Iskandar (2012) mengatakan bahwa suku cadang mempunyai karakteristik yang berbeda dibanding barang persediaan lain. Pola permintaan suku cadang cendering berselang dan tidak memiliki kemiripan dengan distribusi teoritis tertentu, tingkat pelayanan yang diinginkan tinggi karena ketidaktersedianya suku cadang akan menimbulkan konsekuensi biaya yang tinggi, dan harga suku cadang cenderung mahal sehingga biaya untuk menyimpan persediaan membutuhkan biaya yang lebih besar.

Penelitian ini merupakan penelitian studi kasus yang berusaha memcahkan permasalahan dalam sistem nyata. Sistem nyata pengelolaan persediaan suku cadang di perusahaan seringkali tidak mempertimbangkan konsep dan teori yang ada, dan hanya mengandalkan data historis dan intuisi. Penelitian tentang studi kasus persediaan suku cadang pernah dilakukan oleh Aisyati dkk (2012), didapatkan hasil bahwa perusahaan dapat meningkatkan keuntungan jika menerapkan pengendalian persediaan suku cadang dengan metode $\mathrm{ABC}$ dan continuous review dibanding pengelolaan yang ada saat ini. Penelitian lain juga dilakukan oleh Apriandana dan Iskandar (2012), permintaan suku cadang yang tidak pasti diteliti dengan menggunakan simulasi monte carlo dan analisis $\mathrm{ABC}$, hasil yang diperoleh adalah kinerja persediaan lebih baik dibandingkan sistem nyata sebelumnya.

Penelitian ini akan berusaha menganalisis sistem penyimpanan persediaan suku cadang yang ada dengan menggunakan MUSIC-3D. MUSIC-3D adalah kepanjangan dari "Multi Unit Spares Inventory Control-Three Dimensional approach". MUSIC-3D dalam analisisnya menggunakan 3 dimensi pendekatan yaitu consumption value, availability dan critically. Ketiga dimensi tersebut diwakili oleh tiga pendekatan yaitu Sistem ABC (Activity Based Costing), VED (Vital,Essential,Desirable) dan SDE (Scarce, difficult to get, eay to obtain). Pada dasarnya, fungsi dari MUSIC-3D adalah untuk mengidentifikasi item suku cadang berdasarkan konsumsi nilai, ketersediaan dan kelangkaan dengan manajemen yang tepat diantara ribuan item suku cadang yang ada pada suatu perusahaan, serta menentukan item suku cadang yang penting dan memudahkan pengendaliannya. Dengan menggabungkan ketiga sistem diatas, maka manajemen, perencanaan dan pengendalian persediaan akan lebih akurat. Sehingga, PT. XYZ mempunyai dasar pertimbangan saat akan melakukan penyimpanan persediaan suku cadang.

\section{METODOLOGI PENELITIAN}

Penelitian ini merupakan sebuah penelitian studi kasus di PT. XYZ. PT. XYZ merupakan perusahaan farmasi yang menghasilkan obat-obatan dengan mesin berteknologi yang canggih. 
Hampir setiap mesin di PT. XYZ mempunyai suku cadang yang disimpan untuk perawatan berkala dan perbaikan jika ada kerusakan. Obyek penelitian adalah gudang suku cadang yang ada di PT. XYZ. Data - data yang digunakan dalam penelitian ini diantaranya :

1. Data jumlah kebutuhan suku cadang selama 16 bulan

2. Data persediaan suku cadang selama 16 bulan

3. Data lead time suku cadang

4. Data Critically spare parts

Data yang digunakan untuk perhitungan yaitu data suku cadang untuk 12 mesin, baik mesin untuk proses produksi dan juga mesin utilitas. Jumlah item suku cadang yang diteliti adalah 1326 item suku cadang dari sekitar 4756 suku cadang yang ada di gudang, atau $28 \%$ dari seluruh jumlah suku cadang yang ada di gudang. 12 mesin tersebut antara lain :

Tabel 1. Tabel Data Sampel Mesin

\begin{tabular}{|c|l|c|l|}
\hline $\begin{array}{c}\text { No } \\
\text { mesin }\end{array}$ & \multicolumn{1}{|c|}{ Nama Mesin } & No mesin & \multicolumn{1}{|c|}{ Nama Mesin } \\
\hline 1 & Mesin Azo & 7 & Mesin courtoy \\
\hline 2 & $\begin{array}{l}\text { Mesin Folding lipat } \\
\text { multi }\end{array}$ & 8 & Mesin kompresor atlas copco \\
\hline 3 & Mesin siebler & 9 & Mesin cuci besar \\
\hline 4 & Mesin fette 2000 & 10 & Mesin willet \\
\hline 5 & Mesin fette 2090 & 11 & Mesin wsg plus 2000. \\
\hline 6 & Mesin binder & 12 & Mesin Dehumidifier \\
\hline
\end{tabular}

\subsection{MUSIC-3D View of Spares}

Dalam Bukunya, Gopalakrishnan dan Banereji (2004) menjelaskan bahwa MUSIC-3D adalah kepanjangan dari Multi Unit Spares Inventory Control-Three Dimensional approach. MUSIC-3D dalam analisisnya menggunakan tiga dimensi pendekatan yaitu consumption value, availability dan critically. Ketiga dimensi tersebut diwakili oleh tiga pendekatan yaitu sistem ABC, VED dan SDE. Pada dasarnya, MUSIC-3D adalah bentuk penyederhanaan dari ketiga kategori tersebut. Dalam penggabungannya, MUSIC-3D hanya menggambil dua kategori dari tiga sistem diatas. Sebaliknya jika menggunakan tiga kategori dari masing-masing sistem ABC (kategori A,B,C), sistem VED (Vital,Essential,dessirable) dan SDE (Scarce, Difficult to get, Easy to Obtain) akan ada 27 kategori dan itu terlalu kompleks jika dibandingkan delapan kategori yang disederhanakan dalam MUSIC-3D. Beberapa keuntungan menggunakan MUSIC-3D adalah dalam hal perencanaan, peramalan, sistem informasi manajemen, level persediaan, kebijakan pembelian, penentuan service level, antisipasi keusangan, audit perusahaan dan mengendalikan persediaan suku cadang.

MUSIC-3D mencoba untuk mengintegrasikan ketiga sistem diatas. Dalam analisisnya, MUSIC-3D membagi suku cadang menjadi dua bagian yaitu High Consumption value (HCV) dan Low Consumption Value (LCV) yang didapatkan dari sistem ABC. Sedangkan dari sistem VED akan didapatkan dua jenis klasifikasi suku cadang yaitu critically dan non critically. Lead time untuk tiap-tiap suku cadang juga di klasifikasikan menjadi dua yaitu suku cadang yang tergolong Long Lead Time (LLT) dan Short Lead Time (SLT) yang didapat dari analisis SDE. Dengan manggabungkan ketiga sistem diatas, klasifikasi suku cadang akan terbagi menjadi delapan kategori. Seperti pada tabel 2.

Tabel 2. Kategori dalam Analisis MUSIC-3D

\begin{tabular}{|c|c|c|c|c|}
\hline \multirow{2}{*}{} & \multicolumn{2}{|c|}{ High Consumption Value (HCV) } & \multicolumn{2}{c|}{ Low Consumption Value (LCV) } \\
\cline { 2 - 5 } & LLT & SLT & LLT & SLT \\
\hline Critical & 1 & 2 & 3 & 4 \\
\hline Non Critical & 5 & 6 & 7 & 8 \\
& Number 20\% (small) & \multicolumn{2}{c|}{ Number 80\% (large) } \\
& Sales Value 80\% large & \multicolumn{2}{c|}{ Sales Value 20\% low } \\
\hline
\end{tabular}

Dari Tabel 2 dapat diketahui bahwa, suku cadang yang terletak pada kategori 3,4,7 dan 8 mempunyai jumlah item yang banyak tapi frekuensi penggunaannya rendah, sebaliknya suku 
cadang yang ada pada kategori 1,2,5,dan 6 mempunyai jumlah item yang sedikit namun tinggu frekuensi penggunaannya. Item suku cadang pada kategori 3 masa penyimpanannya cukup tinggi, yaitu sekitar 2 tahun, kemungkinan besar tidak akan terjadi stock out, penyimpanannya harus dekat dan mudah diambil, dengan maksimum service level yang mungkin adalah $100 \%$. Dari kategori 3 menuju kategori 4,7 dan 8 kontrol persediaan akan semakin ketat. Untuk item yang ada di kategori 1 dengan LLT dan HCV serta high critically, perencanaan dan pengendalian suku cadang harus sempurna. suku cadang pada kategori 2 hampir mirip dengan kategori 1 namun lebih rendah tingkatannya. suku cadang pada kategori 6 adalah kebalikan dari kategori 3, yakni rendah dalam persediaan.

Klasifikasi ABC merupakan klasifikasi dari suatu kelompok material dalam susunan menurun berdasarkan biaya penggunaaan material itu selama periode waktu tertentu (harga per unit material dikalikan volume penggunaan dari material tersebut selama periode tertentu). Periode yang umum digunakan adalah 1 (satu) tahun. Analisis ABC dapat juga diterapkan dengan menggunakan kriteria lain, bukan semata-mata berdasarkan kriteria biaya saja, namun tergantung pada faktor-faktor penting apa yang menentukan material tersebut. Klasifikasi $A B C$ umum digunakan dalam pengendalian persediaan. Beberapa contoh penerapan seperti : pengendalian persediaan material, produk akhir, persediaan obat-obatan pada apotek, suku cadang dan persediaan produk pada supermarket / toko serba ada.

Pada dasarnya terdapat sejumlah faktor yang menentukan kepentingan suatu material, yaitu :

1. Nilai total uang dari material.

2. Tingkat permintaan (fast moving / slow moving)

3. Kelangkaan atau kesulitan memperoleh material.

4. Kemungkinan kehabisan (stock out) dan juga biayanya (stock out cost).

5. Ruang yang dibutuhkan untuk menyimpan material.

Klasifikasi ABC mengikuti prinsip $80-20$, atau hukum pareto dimana sekitar $80 \%$ dari nilai total inventory direpresentasikan oleh $20 \%$ material inventory.

Jika Sistem $A B C$ berfokus pada tingkat konsumsi suku cadang, VED yang berarti Vital, Essential, Desirable menganalisis suku cadang berdasarkan tingkat kritis dari suku cadang berdasarkan teknologi, produk, desain dan lainnya. Penentuan VED untuk suku cadang adalah berdasarkan fungsinya di sistem produksi. Suku cadang dalam kategori vital adalah item suku cadang yang sangat penting, yang mana tanpa suku cadang tersebut proses produksi bisa terhenti. Essential adalah item suku cadang yang apabila terjadi stock out atau ketiadaan suku cadang akan sedikit mengganggu proses produksi untuk durasi yang pendek. Desirable adalah suku cadang yang mana tanpa suku cadang ini sistem produksi masih tetap bisa berjalan, namun tetap saja dibutuhkan.

Dimensi ketiga dari MUSIC-3D adalah SDE (scarce, difficult to get, easy to obtain), ketersediaan dari item suku cadang berdasarkan pertimbangan lead time dari suku cadang. Suku cadang mungkin dibeli dari pemasok yang berbeda-beda, bisa impor, lokal, workshop perusahaan, suku cadang tambahan mesin dan lain sebagainya. Total waktu lead time biasanya dihitung dari administrasi saat pembelian, waktu produksi dari suku cadang (apabila suku cadang adalah suku cadang khusus dan harus dipesan), waktu transportasi, waktu inspeksi dan lainnya. Tergantung dari prosedur, sistem dan kebijakan pembelian, lead time kemungkinan bisa sampai 36 bulan jika suku cadang impor dan melalui proses tender. Semakin penting dan spesifik suku cadang, lead time akan semakin lama.

\section{HASIL DAN PEMBAHASAN}

\subsection{Klasifikasi berdasarkan $A B C$}

Perhitungan analisis $A B C$ dihitung berdasarkan jumlah persediaan suku cadang yang ada di gudang selama 16 bulan. Diasumsikan bahwa semakin banyak jumlah suku cadang disimpan dalam gudang, maka nilai konsumsi uang dari suku cadang tersebut semakin mahal. Perhitungan $A B C$ sering disebut aturan $80-20$. Artinya, $80 \%$ konsumsi nilai dari persediaan direpresentasikan oleh sejumlah $20 \%$ item suku cadang. Perhitungan analisis ABC pada penelitian ini akan dihitung seluruh suku cadang pada 12 mesin yang menjadi sampel karena suku cadang untuk semua mesin berada pada satu gudang yang sama. Pada Analisis MUSIC3D ini, perhitungan ABC hanya diambil dua kategori dari tiga kategori, yaitu HCV (High Consumption Value) dan LCV (Low Consumption Value). Langkah analisis ABC yaitu :

1. Mengurutkan nilai persediaan suku cadang dari yang terbesar sampai yang terkecil untuk semua suku cadang pada 12 mesin selama 16 periode. 
2. Menghitung prosentase nilai persedian untuk masing-masing suku cadang.

3. Menghitung nilai persediaan kumulatif.

4. Menentukan apakah suku cadang termasuk dalam kategori HCV ataukah LCV.

Contoh perhitungan $\mathrm{ABC}$ pada salah satu mesin :

Tabel 3. Contoh Perhitungan Sistem ABC

\begin{tabular}{|c|c|c|c|c|c|}
\hline No item & persediaan & $\%$ persediaan & $\%$ kumulatif & kategori & \multirow{6}{*}{$\begin{array}{c}71,05 \% \\
\text { consumption } \\
\text { value, } 38 \% \\
\text { items }\end{array}$} \\
\hline 7 & 8 & 21,05263158 & 21,05263158 & $\mathrm{HCV}$ & \\
\hline 12 & 6 & 15,78947368 & 36,84210526 & $\mathrm{HCV}$ & \\
\hline 9 & 4 & 10,52631579 & 47,36842105 & $\mathrm{HCV}$ & \\
\hline 11 & 4 & 10,52631579 & 57,89473684 & $\mathrm{HCV}$ & \\
\hline 10 & 3 & 7,894736842 & 65,78947368 & $\mathrm{HCV}$ & \\
\hline 1 & 1 & 2,631578947 & 68,42105263 & $\mathrm{HCV}$ & \multirow{14}{*}{$\begin{array}{c}28,95 \% \\
\text { consumption } \\
\text { value, } 62 \% \\
\text { items }\end{array}$} \\
\hline 2 & 1 & 2,631578947 & 71,05263158 & $\mathrm{HCV}$ & \\
\hline 3 & 1 & 2,631578947 & 73,68421053 & LCV & \\
\hline 4 & 1 & 2,631578947 & 76,31578947 & LCV & \\
\hline 5 & 1 & 2,631578947 & 78,94736842 & LCV & \\
\hline 6 & 1 & 2,631578947 & 81,57894737 & LCV & \\
\hline 8 & 1 & 2,631578947 & 84,21052632 & LCV & \\
\hline 13 & 1 & 2,631578947 & 86,84210526 & LCV & \\
\hline 14 & 1 & 2,631578947 & 89,47368421 & LCV & \\
\hline 15 & 1 & 2,631578947 & 92,10526316 & LCV & \\
\hline 16 & 1 & 2,631578947 & 94,73684211 & LCV & \\
\hline 17 & 1 & 2,631578947 & 97,36842105 & LCV & \\
\hline 18 & 1 & 2,631578947 & 100 & LCV & \\
\hline Jumlah & 38 & & & & \\
\hline
\end{tabular}

\subsection{Klasifikasi Berdasarkan VED}

Klasifikasi VED atau vital, essential, and desirable dihitung berdasarkan tingkat critical atau noncritical dari suku cadang. Dalam hal ini, penentuan critical atau non critical berdasarkan karakteristik mesin. Jadi, suku cadang yang termasuk dalam mesin kritis diasumsikan sebagai suku cadang critical. Sebaliknya, suku cadang yang termasuk dalam mesin non critical diasumsikan sebagai suku cadang non critical. Mesin kritis adalah mesin produksi yang vital, jika mesin ini berhenti maka membutuhkan jangka waktu lama untuk perbaikan dan berhentinya proses produksi karena perbaikan sangat mempengaruhi proses yang lainnya. Berdasarkan data yang dikumpulkan, diperoleh karakteristik mesin sesuai Tabel 4.

Tabel 4. Klasifikasi Mesin Berdasarkan VED

\begin{tabular}{|l|c|}
\hline \multicolumn{1}{|c|}{ Mesin } & Critical / Non critical \\
\hline Mesin Azo & Critical \\
\hline Mesin Folding lipat multi & Non Critical \\
\hline Mesin siebler & Critical \\
\hline Mesin fette 2000 & Critical \\
\hline Mesin fette 2090 & Critical \\
\hline Mesin binder & Critical \\
\hline Mesin courtoy & Critical \\
\hline Mesin kompresor atlas copco & Non critical \\
\hline Mesin cuci besar & Non critical \\
\hline Mesin willet & Non critical \\
\hline Mesin wsg plus 2000. & Critical \\
\hline Mesin Dehumidifier & Critical \\
\hline
\end{tabular}




\subsection{Klasifikasi Berdasarkan SDE}

Klasifikasi SDE atau scarce, difficult to get, easy to obtain adalah berdasarkan lead time dari masing-masing suku cadang. Lead time adalah waktu yang dibutuhkan untuk memesan barang, mulai dari saat pemesanan sampai barang datang. Panjang lead time biasanya dipengaruhi oleh proses administrasi pembelian, jarak pemasok dengan perusahaan, spesifikasi barang pesanan, dan lainnya.

Ada dua jenis suku cadang yaitu suku cadang import dan suku cadang lokal. Suku cadang lokal mempunyai lead time 1 bulan dalam pemesanannya, sedangkan suku cadang impor mempunyai lead time 6 bulan dalam pemesanannya. Tidak semua suku cadang dalam 1 mesin mempunyai lead time yang sama, beberapa mungkin ada yang berasal dari pemasok lokal, ada pula yang dari pemasok impor. Dengan menggunakan acuan jangka waktu lead time tersebut akan diketahui klasifikasi masing-masing suku cadang berdasarkan SDE.

\subsection{Analisis Menggunakan MUSIC-3D}

Pada penelitian ini tidak ditampilkan perhitungan keseluruhan suku cadang dikarenakan banyaknya data yang digunakan. Berdasarkan pengklasifikasian menggunakan ABC, VED dan SDE, didapatkan delapan kategori sesuai pengklasifikasian menggunakan MUSIC-3D. Dari 1326 item suku cadang yang dianalisis, hasil analisis MUSIC 3D sesuai dengan Tabel 5.

Tabel 5. Tabel Pembahasan Analisis MUSIC-3D View

\begin{tabular}{|c|c|c|c|c|}
\hline & \multicolumn{2}{|c|}{ High Consumption Value (HCV) } & \multicolumn{2}{|c|}{ Low Consumption Value (LCV) } \\
\hline & LLT & SLT & LLT & SLT \\
\hline Critical & $\begin{array}{c}(1) \\
84 \text { item suku } \\
\text { cadang atau } \\
6,33 \% \text { dari } \\
\text { seluruh sampel } \\
\text { suku cadang. }\end{array}$ & $\begin{array}{c}(2) \\
89 \text { item suku } \\
\text { cadang atau } \\
6,71 \% \text { dari } \\
\text { seluruh sampel } \\
\text { suku cadang }\end{array}$ & $\begin{array}{c}(3) \\
581 \text { item suku } \\
\text { cadang atau } \\
43,81 \% \text { dari } \\
\text { seluruh sampel } \\
\text { suku cadang } \\
\end{array}$ & $\begin{array}{c}(4) \\
297 \text { item suku } \\
\text { cadang atau } \\
22,39 \% \text { dari } \\
\text { seluruh sampel } \\
\text { suku cadang }\end{array}$ \\
\hline \multirow[t]{2}{*}{ Non Critical } & $\begin{array}{c}(5) \\
36 \text { item suku } \\
\text { cadang atau } \\
2,71 \% \text { dari } \\
\text { seluruh sampel } \\
\text { suku cadang. }\end{array}$ & $\begin{array}{c}(6) \\
69 \text { item suku } \\
\text { cadang atau } \\
5,2 \% \text { dari } \\
\text { seluruh sampel } \\
\text { suku cadang. }\end{array}$ & $\begin{array}{c}(7) \\
37 \text { item suku } \\
\text { cadang atau } \\
2,79 \% \text { dari } \\
\text { seluruh sampel } \\
\text { suku cadang. }\end{array}$ & $\begin{array}{c}(8) \\
133 \text { item suku } \\
\text { cadang atau } \\
10,03 \% \text { dari } \\
\text { seluruh sampel } \\
\text { suku cadang. }\end{array}$ \\
\hline & \multicolumn{2}{|c|}{$\begin{array}{c}\text { Number } 20 \% \text { (small) } \\
\text { Sales Value } 80 \% \text { large }\end{array}$} & \multicolumn{2}{|c|}{$\begin{array}{l}\text { Number } 80 \% \text { (large) } \\
\text { Sales Value 20\% low }\end{array}$} \\
\hline
\end{tabular}

Kategori 1: 84 buah suku cadang dari 1326 suku cadang atau 6,33\% suku cadang berada pada kategori 1.84 suku cadang ini merupakan suku cadang yang harus ketat dalam pengendaliannya, dikarenakan jumlah yang sedikit namun nilainya tinggi. Suku cadang pada kategori 1 mempunyai lead time yang panjang dan termasuk suku cadang untuk mesin kritis sehingga harus dipastikan stoknya tersedia saat dibutuhkan.

Kategori 2 : 89 buah suku cadang dari 1326 suku cadang atau $6,71 \%$ suku cadang berada pada kategori 2. Kategori 2 mempunyai karakteristik yang mirip dengan kategori 1. 84 suku cadang ini merupakan suku cadang yang harus ketat dalam pengendaliannya, dikarenakan jumlah yang sedikit namun nilainya tinggi. Suku cadang pada kategori 1 mempunyai lead time yang pendek namun, termasuk suku cadang untuk mesin kritis. Dengan lead time yang pendek perusahaan lebih mudah memastikan ketersediaan suku cadang saat dibutuhkan, sehingga tidak harus menyimpannya dalam jangka waktu yang lama untuk menghindari keusangan.

Kategori 3 : 581 buah suku cadang dari 1326 suku cadang atau $43,81 \%$ suku cadang berada pada kategori 3. 581 suku cadang ini tidak begitu besar nilainya namun 
dibutuhkan untuk mesin yang kritis, artinya tingkat ketersediaan harus tinggi untuk menghindari out of stock. Dikarenakan lead time yang panjang, pengadaan suku cadang pada kategori ini harus dipersiapkan jauh-jauh hari.

Kategori 4 : 297 buah suku cadang dari 1326 suku cadang atau $22,39 \%$ suku cadang berada pada kategori 4. 84 suku cadang ini merupakan suku cadang mudah dalam pengelolaannya, karena lead time yang pendek, nilainya yang tidak terlalu besar namun digunakan untuk mesin yang kritis, sehingga tetap memerlukan pengelolaan yang tepat agar selalu tersedia jika diperlukan.

Kategori 5 : 36 buah suku cadang dari 1326 suku cadang atau 2,71 suku cadang mempunyai karakteristik lead time yang panjang, nilai yang tinggi namun jumlah yang sedikit. Dikarenakan suku cadang ini digunakan untuk mesin yang tidak kritis maka persediaanya dapat dikendalikan berdasarkan waktu pembelian.

Kategori 6 : 69 buah suku cadang dari 1326 suku cadang atau 5,2\% suku cadang berada pada kategori 6.69 suku cadang ini merupakan suku cadang yang harus cermat dalam pengadaannya. Kategori 6 mempunyai karakteristik nilai yang tinggi namun mempunyai lead time yang pendek dan untuk mesin yang tidak kritis.

Kategori 7 : 37 buah suku cadang dari 1326 suku cadang atau 2,79\% suku cadang berada pada kategori 7. 37 suku cadang ini merupakan suku cadang yang cenderung mudah dalam pengendaliannya. Dalam pengadaanya kategori 7 mempunyai lead time yang panjang namun tidak kritis dan nilainya yang rendah.

Kategori 8 : 133 buah suku cadang dari 1326 suku cadang atau $10,03 \%$ suku cadang berada pada kategori 8. 133 suku cadang ini merupakan suku cadang yang paling mudah dalam pengelolaannya. Meskipun jumlahnya banyak, namun nilai dari suku cadang yang rendah dan digunakan untuk mesin yang tidak kritis. Kategori 8 juga tidak memerlukan rencana strategis karena lebih banyak digunakan pada level teknis.

\section{KESIMPULAN}

Berdasarkan analisis yang telah dilakukan menggunakan MUSIC-3D diperoleh bahwa $6,33 \%$ dari seluruh sampel suku cadang berada pada kategori 1, 6,71\% berada pada kategori 2, 43,81\% berada pada kategori $3,22,39 \%$ berada pada kategori $4,2,71 \%$ berada pada kategori 5, 5,2\% berada pada kategori 6, 2,79\% berada pada kategori 7, dan 10,03\% berada pada kategori 8. Hasil analisis ini kemudian akan digunakan perusahaan sebagai bahan pertimbangan dalam hal pengadaan dan penyimpanan persediaan suku cadang.

\section{SARAN}

Persediaan adalah sumber daya yang tertahan, dan penanganan sumber daya yang ada dalam inventory sangat erat hubungannnya dengan aktifitas produksi. Begitu juga dengan inventory suku cadang. Pengendalian inventory suku cadang akan lebih akurat jika melibatkan aktifitas pada waktu proses produksi yang berimbas pada aktifitas mesin, dimana mesin ini lah yang menjadi konsumen dari pada suku cadang. 


\section{DAFTAR PUSTAKA}

Aisyati, A., Jauhari, W. A., \& Muhbiantie, R. T. (2012). Kebijakan Persediaan Suku Cadang Pesawat Terbang untuk Mendukung Kegiatan Maintenance di PT GMF Aero Asia dengan Menggunakan Metode Continuous Review. Seminar Sistem Produksi X, (hal. 1-7). Bandung.

Apriandana, D., \& Iskandar, P. B. (2012). Peningkatan Kinerja Sistem Persediaan Suku Cadang Alat Boom Sprayer dengan Simulasi Monte Carlo. Studi kasus PT. XYZ. Seminar Sistem produksi $X$, (hal. 28-34). Bandung.

Gopalakhrisnan, P., \& Banerji, A. K. (2004). Maintenance and Spareparts Management. PHI Learning Pvt. Ltd. 